\title{
Analysis of Three Significant Sustainable Development Goals (SDGs) in China
}

\author{
Hongyi Tao ${ }^{1, *}$, Yu Chen Liu $^{2}$ \\ ${ }^{1}$ The Faculty of arts, The University of Melbourne, Melbourne, VIC 3000, Australia \\ ${ }^{2}$ The Faculty of Science, The University of Melbourne, Melbourne, VIC 3000, Australia \\ ${ }^{*}$ Corresponding author. Email: hongyit1@student.unimelb.edu.au
}

\begin{abstract}
This article analyzes the current status of three Sustainable Development Goals (SDGs) in China and attempts to address how to achieve three goals in China. Firstly, the overall background of the Sustainable Development Goals and each of the three goals will be introduced. It then explains the reason why the three goals in China need to be resolved. The article analyzes some recent policies related to these goals and real existing problems. More importantly, the essay expounds the reasons for these problems and proposes further policy recommendations in China.
\end{abstract}

Keywords: SDGs, China, quality education, no poverty, climate change, policy

\section{INTRODUCTION}

On September 25, 2015, the 193 member states of the United Nations formally adopted 17 sustainable development goals at the summit took place at United Nations Headquarters in New York. These 17 goals have learned from the valuable experience of the eight Millennium Development Goals. On the one hand, the unfinished Millennium Development Goals agenda will continue to be completed. On the other hand, the problems of the three dimensions of society, economy, and environment will be solved entirely in an integrated way between 2015 and 2030. More importantly, the United Nations has made a historic commitment: the primary goal is to eradicate poverty forever in every corner around the world and not to exclude anyone from development. In this article, it will explain the three SDGs and why we chose them. The article will then introduce each of three SDGs. Finally, it will recommend some policies and expound their reasons for these SDGs.

\section{I SDGs}

The first goal, called quality education, aims to provide the world with an inclusive and equitable education that promotes lifelong learning opportunities for all [10]. Furthermore, this goal mainly focuses on four aspects. 1. The primary school enrollment rate in poor areas. 2. the lack of acquisition of fundamental skills for female. 3. Improving children's physical, psychological, and learning development. 4 . The balance between vocational education and higher education [10].

\subsection{Why is this goal important in China?}

Quality education accurately refers to two main problems of education in China. Firstly, the illiteracy rate of female and male aged 15 and over in 2017 is $7.34 \%$ and $2.42 \%$ respectively [3]. Secondly, in 2017, the number of students enrolled in undergraduate in regular was 7.615 million and in secondary vocational education is only 5.824 million [3]. As a result, it is obvious that before 2017, the education resources distribution is unfairly even. Therefore, this goal is not only important for China but also its comprehensive solutions to the problems will also provide valuable experience for the world.

\subsection{How to improve quality education in China?}

In 2006, two policies were issued to promote gender equality in compulsory education and to enhance vocational education system. First, "The Compulsory Education Law" was revised, and a compulsory education supervision mechanism was established [4]. From 2006 to 2017, the illiterate rate for both male and female has dropped significantly, but the illiterate female rate is still larger than male [3]. Second, "The Eleventh Five-Year Plan" had led to an increase in the enrollment scale rate in secondary vocational education [9]. The number of students enrolled had increased to 8.1 million in 2008 [3]. The enrollment of secondary vocational education and undergraduate in regular has been roughly the same [3]. However, since 2009, this increase has declined. In 2017, the rate dropped back to 5.824 million [3]. There are several reasons for two problems as follows: 


\subsubsection{The higher illiteracy rate of female}

(1) Traditional Chinese agriculture concept: parents believe that boys have more cost-effective to go to school.

(2) The shortage of educational resources in poor areas.

\subsubsection{Inequality between Vocational education and higher education}

(1) Children are expected to receive higher education.

(2) A vicious circle of the poor quality of teaching and the source of students in vocational education.

For these reasons, there is a policy: "online education" and "offline motivation". The "online education" means that online education, such as MOOC, can help 10,000 people attend a class online at the same time, and students can choose famous teachers in various subjects what they like [6]. Therefore, online education can basically resolve the shortage of educational resources and the vicious circle. However, this cannot avoid antiquated ideas in China, so "offline motivation" means that the government helps people update their concepts by organizing community activities in rural areas.

\subsubsection{The higher illiteracy rate of female}

(1) Presenting the positive effects of education on females, such as marriage and career.

(2) Compared with males, what advantages of the female are at school.

(3) providing education planning and career planning services.

\subsubsection{For vocational education,}

(1) Introducing the advantages of blue-collar social status advantages, incomes, and career prospect.

Therefore, the policies are of benefit to resolve the two problems in quality education.

\section{II SDGs}

The second goal is no poverty. The United Nations, through using purchasing power parity (PPP) in 2011, defines the international poverty line as 1.90 US dollars per person per day [10]. In $2015,10 \%$ of workers and their families in the world still lived below the international poverty line [10]. In addition, young people between the ages of 15 and 24 are likely to become working poor. In $2015,16 \%$ of employed youth lived below the poverty line [10]. Therefore, governments around the world commit to eradicating poverty before 2030 .

\subsection{Why is this goal important in China?}

This goal is basically consistent with the aim targeted measures in poverty alleviation (TPA) proposed by Chinese President Xi Jinping in November 2013 [14]. In $2017,3,046$ out of every 10,000 people in rural areas lived in poverty [3]. Actually, the poverty rate in these areas is larger because the standard of poverty is 2,300 RMB per person per year (0.94 US dollars) [3]. There is still a big gap compared with the international poverty line (1.90 US dollars). Therefore, poverty is a pressing problem in China. Besides, most poor people are distributed in underdeveloped areas in the world, and this distribution is the same as China. There also can be seen as a pilot country to achieve this goal, so it is important to give priority to the goal in China.

\subsection{How to mitigate poverty in China?}

In order to solve poverty by 2030 , China has established a TPA mechanism since 2013. Local governments should identify poor areas and establish electronic files for each poor family to ensure poverty alleviation effective, and TPA's specific measures include ten projects, and five measures [13]. Although TPA has great performance, it still has the three problems of available land in short supply, high-cost of industry, and the loss of labor force in China because the way of TPA is mainly to develop industry [14]. In order to deal with the three problems, the recommended policy is Three Land consolidation projects. The policy should depend on different rural areas.

\subsubsection{New agricultural consolidation project}

(1) Agricultural land and forest planting

The categories: crops, precious flowers, precious herbs, precious trees

Considerations: climate, soil, rainfall, sunlight, elevation, irrigation distance

(1) Breeding planning

Considerations: terrain, temperature, humidity, climate, The categories of the breeding industry: poultry, livestock, aquaculture

\subsubsection{Industrial land consolidation project}

Land planning: ownership right, contract right and management right of land should belong to farmers. If the residential land and wasteland are changed into industrial land, farmers can work there to earn money, and they can also get rent from industrial land every year. Of course, this project needs to ensure that arable land minimum cannot be broken in China. 


\subsubsection{Mixed consolidation}

The local governments can combine with both models according to different situations, but the strategy is based on no pollution impact on the operation of new agriculture. In doing so, the three models can avoid the three problems to some extent of available land in short supply, high-cost of industry, and the loss of labor force in rural area.

For example, Song Jiagou Village Fuping County is located in the western part of Hebei Province. The unused 171,520 hectares of land were developed to improve the irrigated area of 178.68-hectare in 2015 [14]. The government establishes forest fruits industry by attracting investment, and a modern agricultural demonstration zone. This method helps 182 households of which 95 households are the poor households and address the lack of land, high-cost of industry, and the loss of labor [14].

\section{III SDGs}

The third goal is to combat the biggest threat to development, climate change. Since carbon emissions have been rising steadily over the past decades, global temperatures begin to rise. In order to mitigate climate change, in April 2016, 175 member states signed a landmark Paris Agreement, aimed to maintain global temperatures less than 2 degrees Celsius above the pre-industrial level and to pursue further efforts to limit 1.5 degrees Celsius [10]. The Paris Agreement requires Parties to determine their"nationally determined contributions" (INDC). The progress of the Paris Agreement will be tracked every five years through global inventory work [5].

\subsection{Why is this goal important in China?}

The main factor of global climate change, as is well known, is greenhouse gases, such as carbon dioxide [CC2], methane $[\mathrm{CHJ}]$ and several others are mixed in the global atmosphere, and their accumulation will have negative impacts on the earth, which is related to the survival of mankind [11]. The emissions from fossil fuel and cement manufacture in China from 2005 to 2011 were counted by various agencies. For example, the International Energy Agency provides fossil fuel emissions from $5000 \mathrm{Mt}$ to about 7000Mt [7]. Second National Communication provides the data of cement manufacture of about 400 to $600 \mathrm{Mt}$ [7]. This indicates that greenhouse gas emissions in China have been increasing. Therefore, it is important to engage China to participate in overcoming climate change.

\subsection{How to improve climate change in China?}

On April 24, 2014, The Twelfth Standing Committee of the National People's Congress amend the People's Republic of China Environmental Protection Law and announce the date of implementation, January 1, 2015 [8]. The law stipulates that in the territory of the People's Republic of China and other sea areas under the jurisdiction of the People's Republic of China, enterprises and institutions that directly discharge taxable pollutants to the environment should pay an environmental protection tax [8]. Helping local environmental protection, the State Council decides that environmental protection taxes are all used as local financial revenue [9]. In 2015, emissions in the air began to decline in China because of the implementation of the law. For example, from 2015 to 2017, the emissions of sulphur dioxide dropped from 1859.12 to 875.40 [3]. However, China's Fossil CO2 emissions are still close to 10Gt [2]. Therefore, China should concentrate on how to reduce carbon emissions.

The recommended policy is a coordination policy between the carbon tax and carbon emissions trading.

\subsubsection{The Carbon tax}

The Carbon tax aims to reduce carbon dioxide emissions and mitigate global warming [1]. When governments impose a carbon tax on manufacturers, there are two situations: (1) manufacturers will pass these costs on customers. (2) manufacturers will try to find new energy.

\subsubsection{Carbon emissions trading}

Carbon emissions trading is to protect the environment by using a market-oriented economy and allows companies to buy the available quota from other companies or countries [1]. There are, however, two problems with carbon emissions trading.

(1) Operation costs of carbon emissions trading.

(2) Initial emission allocation right.

\subsubsection{A Coordination policy}

The Carbon tax is reflected in prices, while carbon emissions trading is embodied in quantity. The combination of the two methods is a complementary relationship. In terms of the relationship, carbon tax and carbon emissions trading can be divided into three choices. (1) a carbon tax: the government can relax other taxes, which can make carbon tax become a process of incremental change.

(2) carbon emissions trading: governments provide trade subsidies. It also can promote a carbon emissions trading market to operate well.

(3) Of course, manufacturers can choose them both. For example, a manufacturer decides to pay a part of the carbon tax a year. They can always focus on the fluctuations in the carbon trading market, and purchase the quotas at the lowest possible prices. In doing so, they can enjoy two discounts from the government.

No matter which way manufacturers choose, there are no extra government expenditures. Governments only play the 
role of a distributor. However, this coordination can significantly increase people's attention to carbon emissions and encourage them to search for new energy sources, thereby reducing carbon emissions.

\section{CONCLUSION}

This article introduces the overall background and history of the Sustainable Development Goals and mainly focus on the three significant goals in China. The article also provides an insight into the reason why three goals are important in China or the world. In order to reach the goals, although the Chinese government designs many policies and strategies, The real gaps in China are still identified by analyzing various policies and strategies during implementation processes. Regarding the gaps, the article tries to give many recommendations to achieve the three SDGs mentioned above, in China.

\section{REFERENCES}

[1] Elkins, P, \& Baker, T, 2001, 'Carbon taxes and carbon emissions trading', Journal of economic surveys, vol. 15, no. 3, pp. 325-376.

[2] Global Carbon project 2018, 'Global Carbon budget 2018', GCP, vol.10, no. 4 pp.2141-2194.

[3] Jizhe, N 2018, China Statistical Year Book, Bureau of Statistics of China, Beijing, viewed December 2018, $<$ http://www.stats.gov.cn/tjsj/ndsj/2018/indexeh.htm>.

[4] National People's Congress (NPC) 2006 Compulsory Education Law of the People's Republic of China (2006 Revision), Beijing, viewed 29 June 2006, $<$ http://english.gov.cn/archive/laws_regulations/2014/08 /23/content 281474983042154.htm>

[5] Peters, G. P, Andrew, R. M, Canadell, J. G, Fuss, S, Jackson, R. B, Korsbakken, J. Le quere, C, \& Nakicenovic, N 2017, 'Key indicators to track current progress and future ambition of the Paris Agreement', Nature Climate Change, vol. 7, no. 2. pp. 118.

[6] Rodriguez, C. 2012, 'MOOCs and the AI-Stanford Like Courses: Two Successful and Distinct Course Formats for Massive Open Online Courses', European Journal of Open, Distance and E-Learning, viewed 05th July 2012, $<$ http://www.eurodl.org/materials/contrib/2012/Rodrigu ez.pdf $>$.

[7] Songli, Z, 2014, 'Comparison and analysis of CO2 emissions data for China', Advances in Climate Change
Research, vol. 5, no. 1, pp. 17-27.

[8] The Twelfth Standing Committee of the National People's Congress (SCNPC) 2014 Environmental Protection Law of the People's Republic of China (2014 Revision), Beijing, viewed 24 April 2014, $<$ http://www.china.org.cn/english/government/207462.h tm>.

[9] The state Council 2006, The Eleventh Five-Year Plan, Beijing, viewed 14 March 2006, $<$ http://www.gov.cn/english/special/115y_index.htm>.

[10] United Nations Department of Economic and Social Affairs 2016, The Sustainable Development Goals Report, New York, viewed 1 January 2016, $<$ https://unstats.un.org/sdgs/report/2016/>.

[11] Wiener, J. B, 2007, 'Climate change policy and policy change in China', $U C L A L$, vol. 55, no. 6 . pp.1805-1826.

[12] Xiaohua, Q 2006, China Statistical Year Book, Bureau of Statistics of China, Beijing, viewed December 2006 , $<$ http://www.stats.gov.cn/tjsj/ndsj/2006/html/D0413e.ht $\mathrm{m}>$.

[13] Yucheng, L, Bao zhong, S \& Yansui, L 2016, 'Realizing targeted poverty alleviation in China: People's voices, implementation challenges and policy implications', China Agricultural Economic Review, Vol. 8, no. 3, pp. 443-454.

[14] Zhou, Y, Guo, Y, Liu, Y, Wu, W, \& Li, Y 2018 , 'Targeted poverty alleviation and land policy innovation: Some practice and policy implications from China', Land Use Policy, vol.74, pp. 53-65. 